\title{
SANITATION DURING THE PAST TWENTY-FIVE YEARS.*
}

By H. O. PILKIngton, M.R.C.S., Eтc.,

Medical Officer of Health of Preston, President of the North-Western Branch of the Incorporated Society of Medical Officers of Health.

I HAVE chosen the above as the subject for a short Inaugural Address as President of this Association, because the period dealt with is that in which sanitation and sanitary matters generally have especially progressed, and because it is one during which I have had practical experience as a medical officer of health.

To the majority of those engaged in the work of improving and protecting the public health, the advance made-say from year to year-must not unfrequently appear slight and immaterial, so much so as to lead at times to a feeling of disappointment and failure; but if a much longer period be taken, and a comparison be made between the sanitary condition of the country as it was then and as it is at the present day, the advance made will be found to be very considerable, of a widely embracing character, and such as to afford reasonable grounds for congratulation on the part of those to whose efforts the improvement has been mainly due.

After the passing of the Public Health Acts of 1872 and 1875, the various authorities having charge of boroughs, townships, and rural districts began the work of appointing medical officers of health, who were to give either a part or the whole of their time to the work of superintending the sanitation of the particular district for which they were appointed. The office was not a new one, since it had existed for some years previously under the authority of various Acts of Parliament-notably, the Towns Improvement Clauses Act (1847), the Public Health Act (1848), and the Artisans' and Labourers' Dwellings Acts of 1868. In many cases it was expected, if not actually expressed in so many words, that the officer so appointed would give as little trouble as possible, and interfere as little as possible with the existing condition of affairs. It speaks well for those undertaking the duties of health officers that this feeling has now in a great measure passed away. The medical officer and his attendant inspectors are no longer regarded by property owners and the general public as troublesome inquisitive officials, whose eyes are to be hoodwinked and whose visits discouraged as far as circumstances will permit. True, there are

* Read at the Annual Meeting of the Branch, October, 1895. 
still owners of property as yet not sufficiently educated to see that a clean and well-appointed house invites a reliable and trustworthy tenant, and that it is false economy to grudge the expenditure of the money necessary to keep a dwelling in a wholesome and sanitary condition. But by the majority of people the medical officer of health has in the present day come to be regarded as the custodian of the public health, the official to whose services appeal is made, not to cure disease, but to remedy the conditions likely to cause it, and to alleviate many of the evils which tend to render life less worth living.

The change has of course been gradual, and has been more especially noticeable during the last few years of the period with which I am dealing, and while in a great measure due to an increasing knowledge of sanitary matters amongst the people, it has, at any rate, been fostered and encouraged by the firmness and tact with which the various health officers throughout the country have discharged the duties of their office.

Violent reforms are to be avoided, especially when dealing with vested interests and the rights of property, and the fact that the change of feeling has been gradual renders it all the more likely to be permanent and well established. "Slowly but surely" should be the motto of the sanitary reformer, and just as he is the best police officer who, without having many prosecutions, still keeps his beat free from deeds of violence, robbery, or drunkenness, so the medical officer of health may be accounted the most efficient who succeeds in carrying out his measures of reform and improvement by persuasion or official notice without the necessity of an appeal to the law.

Amongst the working classes-and these, forming as they do the great bulk of the population, decide in a great measure the sanitary condition of a town-the change during the past twenty-five years is well marked. The worst class of houses, the great majority of those built back to back, and almost the whole of the cellar dwellings, have been closed. In some instances the area resulting from demolished houses has been left as a breathing space; in others, the dwellings have been converted into workshops, or fresh streets with greatly improved houses have been erected on the site.

In all old towns, such as Preston, one great difficulty to be faced has been the small confined back-yard, a large portion of which is taken up by the privy and the ashpit, the latter often unnecessarily large and always objectionable. In the worst cases these have gradually been converted into waterclosets, with pails for the dry 
ashes. In my opinion this is by far the best method for the removal of waste and excrementitious matter from a household. Of course, wherever the water-carriage system is adopted there must be a constant and an abundant supply of water, the drains and sewers must be well laid and in good order, and there must be a proper means for the disposal of the liquid sewage.

In Preston the latter is conveyed to a large area of reclaimed land near the mouth of the river, and there is distributed as required over various parts of the farm. The contents of the pails are collected once a week, or oftener as may be, and are conveyed to one of two destructors and there burnt.

I lay stress upon the ashpail, because this should always be the accompaniment of a watercloset. If an ashpit be allowed to remain, it becomes the receptacle for all kinds of decaying animal and vegetable matter, and this, remaining often for a considerable length of time, causes a nuisance but little inferior to that of the original middenstud.

This conversion of the privy-midden system to one of watercarriage has had the effect of materially improving many of the worst parts of the town, typhoid fever and diarrhoea having been diminished, both as regards amount and severity, in the districts thus dealt with. As regards the sanitary accommodation in the majority of the mills and workshops, marked improvement has also been effected, and since a great part of the operative's lifetime is spent at the scene of his labours, it is necessary that this should be inspected and cared for.

The older mills were apparently built with little, if any, regard for the operatives' health and comfort, the privy accommodation being exceedingly cramped as to space and rude and primitive in construction. In most cases the closet opened directly from the workroom, and the excrement was discharged down an iron pipe from the top story to the cesspool below the level of the ground. This pipe in the course of time and from constant use became internally fouled and coated with filth, while the offensive and dangerous odours given off from its surface and from the festering contents of the cesspool were drawn by the warm air into the several stories of the building.

Although manufacturers, like the majority of people, are somewhat averse to spending money for the benefit of others (and this more especially at the present day, when the margin of profit is reduced to a narrow limit), still, I have always found them amenable to reason, and anxious to remedy evils when these have been once pointed out and thoroughly explained to them. As a conse- 
quence, the old evil-smelling cesspool-a nuisance at all times, but more especially when being emptied-has now almost entirely disappeared, and in its place will be found some form of trough-closet, or, what is better still, a series of earthenware closets fixed upon a common drain, and automatically flushed by a syphon cistern of sufficient capacity placed at the upper end of the row. The same improvements have also been extended to the public schools of the town, where formerly the privies were a source of danger, and not seldom a cause of sickness to the children who frequented them.

Better ventilation and therefore a purer atmosphere has also been required in schools, factories, and workshops, and this care for the well-being of the occupants has not only improved their health, but has also served to teach a lesson which they may well be expected to carry out in the management of their own homes.

Measures for the prevention of the smoke nuisance have not been very successful. With new mills, where ample boiler room is provided, it becomes a comparatively easy matter to prevent the emission of dense smoke, but in the older factories little good seems to result from the various appliances which from time to time are brought forward by their inventors. But in the present day, when the aim of the manufacturer is directed towards utilizing his waste products and economizing his labour and fuel, it may surely be expected that some certain method will be devised to prevent the emission of unused carbon and the consequent pollution of the atmosphere.

One insanitary condition, prevalent in almost all manufacturing towns, was the keeping of animals, such as swine and various kinds of poultry, in the already crowded back-yards. This was an evil to which the attention of the first appointed medical officers of health was, as a rule, at once directed, and although the nuisance is a recurring one, it is far less common than it was some twenty years ago. People have in some degree learnt the value of open space and free ventilation about their dwellings, and the folly of vitiating the air with the foul odours inseparable from animals kept in such confined situations.

I have said but little as to the part played by legislation towards the improvement of the public health, but it is through the various Acts which have been passed-more especially in recent years-that the health officer obtains the powers necessary to enable him to do his work and carry out the necessary reforms. Indeed, there are now so many separate Acts bearing upon sanitary matters, and so more or less intimately affecting medical officers of health, that it would be of the greatest service if the Public Health Laws could 
only be revised, consolidated, and amended. It is to be regretted that all Parliamentary measures relating to sanitation are not progressive and in keeping with the present advance of sanitary science. The recent Vaccination Act, with its "conscientious objection clause," is so distinctly retrograde, and so certain to be fraught with disastrous consequences before very many years have elapsed, that it seems strange how it could have been passed, especially in the face of the object-lessons furnished by recent outbreaks of small-pox, and in opposition to the skilled and emphatic evidence of those best qualified to speak on the subject.

In addition to the sanitary improvements which I have briefly discussed, and which are mainly instigated and brought about by the action of the medical officer of health, in all large towns considerable sums of money have been expended on matters directly affecting the health and comfort of the population. Parks and playgrounds have been laid out, and baths and washhouses erected, to afford the means for exercise, recreation, and bodily cleanliness; while libraries, reading-rooms, museums, picture-galleries, and technical schools give ample opportunity for mental culture.

Streets have been widened, and are now better paved, lighted, and scavenged ; the water-supply is of good quality, and more abundant and constant; while in many cases, at any rate, the difficult problem of the satisfactory disposal of the sewage has been grappled with and solved. Hospitals have been provided for the reception and isolation of patients suffering from infectious disease; ambulances are at hand for their speedy and more easy removal; while disinfection of the house and bedding is carried out in a thorough and scientific manner.

In those towns which have been constituted port sanitary authorities special hospitals have been erected for the treatment of cases of sea-borne cholera, and these, in conjunction with a vigilant inspection of foreign-coming vessels, form a cordon of safety around the coast, protecting the whole country from the risk of invasion.

Nor must I omit mention of the improvement in the staff which forms the medical officer's little army in his fight against discomfort, disease, and death. The sanitary inspector of the present day-active, vigilant, and disciplined-is far ahead of the nuisance inspector of bygone years, an officer who frequently combined other municipal duties with those connected with sanitation.

The death-rate is frequently, though not seldom erroneously, taken as a standard by which to judge of the sanitary condition of a given town or a particular district. With all these improved 
conditions, it may not unreasonably be expected that the rate of mortality will be found to have been materially reduced. Such, indeed, has been the case, and though here, again, I deal only with conditions and figures relating to Preston, they may be taken as a type of what has occurred throughout the whole country. During the twenty-five years, from 1848 to 1872 (inclusive), the rate of mortality averaged $29 \cdot 34$ per 1,000 per annum; while in the succeeding twenty-five years, from 1873 to 1897 , it averaged $25 \cdot 13$ per 1,000. But dividing the last twenty-five years into five quinquennial periods, it will be found that the average rate per annum has been-

$\begin{array}{llll}1872 \text { to } 1877 & \ldots & 30 \cdot 38 \text { per } 1,000 . \\ 1878 \text { to } 1882 & \ldots & 26 \cdot 04 & , \\ 1883 \text { to } 1887 & \ldots & 25 \cdot 71 & " \\ 1888 \text { to } 1892 & \ldots & 25 \cdot 23 & , \\ 1893 \text { to } 1897 & \ldots & 21 \cdot 92 & \text { ", }\end{array}$

This represents a well-marked and steady decline; and in considering it, it must be remembered that sanitary changes and improvements do not necessarily make themselves felt at once-at any rate, do not at once make a sensible impression upon the rate of mortality.

The type of disease has also been altered. Certain diseases are rarely, if ever, met with; epidemics are of less frequent occurrence, of a milder form, and more easily controlled. If even I had the time at my disposal, it hardly comes within the province of this paper to deal with recent researches into the causation of disease, with fresh aids to diagnosis, and with the means which science now places in our hands for the prevention and treatment of various forms of illness.

It might almost be supposed that, after a time, the services of a medical officer of health would no longer be required, that with continued improvements his very raison d'être would cease; but as I have shown, his work is constantly increasing, and, with the advance of science, will continue to increase. As in everything else, so in preventive medicine, science is constantly making advances; and though a medical officer of health may have neither the time nor the ability himself to conduct researehes, he must, at least, be able to weigh up the work of others, and to appreciate its value. I have sometimes thought that there is a danger of the future health officer being too scientific, too much given to propounding and criticising fresh theories, and too little given to actual practice-in short, that he may be a young savant quite capable of tracing the progress of a bacillus along a silk thread, or observing 
the action of a mierobe when confronted with a plate of broth, but with a soul above investigating a blocked drain or a defective soilpipe.

And yet I doubt not that the medical officer of health will keep pace with other improvements, will keep abreast with the times, and that in the service of hygiene and the public health there will always be found men capable of doing credit to themselves and honour to this-not the least honourable-branch of the noble science of medicine.

\section{MINOR ILLNESSES IN SCHOOLS.}

TuE question of overwork in the middle and high schools of Germany, so hotly discussed some years ago, has been reopened by Dr. K. SchmidMonnard (Ztsch. f. Schulgesund pfl., 1897, Nos. 11 and 12) in a report on the medical examination of 5,100 boys and 3,200 girls, as nearly comparable as could be in age, social position, and home surroundings. He found an excess of 5 to 10 per cent. of illness generally among girls over boys, and a like excess, most marked among girls, in the lower classes of the high schools over the like classes in middle schools. In the upper classes of the high schools the proportions were reversed, from the excessive work imposed on lads seeking the abiturient's certificate as a pass to the Universities.

The curve, which in middle schools began to fall about the twelfth or thirteenth year, continued to rise in high schools till it reached its maximum in the Ober-prima; the rise amounting to 74 to 80 per cent. in girls' high schools where there was an afternoon attendance, although naturally the weaker girls had left without attaining the highest classes. Headaches, epistaxis, and sleeplessness, were 50 to 100 per cent. more frequent among girls than among boys.

The percentage of children wearing spectacles on entrance was 0.5 to 1.5 in middle, and practically $n i l$ in the high schools, but in each it rose class by class to 5 per cent. in the upper classes of the former, and to 23 per cent. for boys, and 13 per cent. for girls in the last. But perhaps the most striking contrast was presented by the lads in the Ober-selcunda of those high schools in which the afternoon was spent in schoolwork, and of others in which it was devoted to gymnastics, tennis, and out-door athletics, the percentage in the former being 43 to 44 , and in the latter, 7 to 17 .

School hours vary with the age from $4 \frac{1}{4}$ to $5 \frac{1}{4}$ at seven years, to $9 \frac{1}{2}$ to 12 at eighteen to twenty years, but if home-work be taken into account, the $9 \frac{1}{2}$ of a boy of fifteen easily becomes 15 , which Dr. SchmidMonnard rightly denounces as "ungeheuerlich"!

In the case of girls, too, there is the music, for which the parents are chiefly to blame. He found that 50 per cent. in middle schools practised at horne, from 4 or 6 to 12 , or even 16 hours weekly, and in the high schools rarely less than 12 hours, and often more- 90 per cent. suffering from headaches.

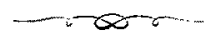

